\title{
The importance of ultrasonography in the diagnosis and treatment of musculoskeletal problems of haemophilia A
}

\author{
Adriana Diaconu ${ }^{1}$, Oana Rizea ${ }^{2}$, Horatiu Vultur ${ }^{1}$ \\ ${ }^{1}$ Paediatric Department, Fundeni Clinical Institute, \\ "Carol Davila" University of Medicine and Pharmacy, Bucharest, Romania \\ ${ }^{2}$ Radiology Department, Fundeni Clinical Institute, \\ "Carol Davila" University of Medicine and Pharmacy, Bucharest, Romania
}

\begin{abstract}
Haemophilia A, defined by a deficiency of clotting factor VIII, can cause bleeding in various locations, especially on muscles and joints. For these patients, ultrasonography plays a very important role in the monitoring and shaping of the replacement treatment with factor VIII, by confirming the time when full clinical-imaging complete remission is obtained.
\end{abstract}

Keywords: haemophilia A, ultrasonography, musculoskeletal issues

\section{INTRODUCTION}

Congenital haemophilia $\mathrm{A}$ is a clotting disorder, with X-linked transmission, characterized through a deficiency of factor VIII. The gene that controls the synthesis of the clotting factors is located on the $\mathrm{X}$ chromosome, therefore it only appears in male patients and it is represented by bleedings with various localizations: cutaneous/subcutaneous, mucous, muscular, cell spaces, visceral, joints (haemarthrosis) (1).

The normal level of the FVIII concentration varies between 50 and $150 \%$. Therefore, the severity degrees of haemophilia are defined in relation to the deficiency of F VIII:

- Severe (F VIII < 1\%);

- Moderate (F VIII: 1-5\%);

- Mild (F VIII: 5-40\%).

Haemarthroses are the most frequent type of bleeding (70-80\% of the cases) and are characterized by the following: predominantly affect the large joints (knees, elbows, ankles, fists, hips), can be caused by a minor traumatism (for instance, a longer walk) and they have a tendency to relapse (1). In the absence of replacement treatment, they evolve from a pure haemarthrosis to a haemophilic arthropathy and, later, to joint ankylosis. The synovial and the bone cartilage can be altered, with various degrees of joint mobility reductions (2).

Substitution treatment consists of the intravenous administration of F VIII concentrates obtained from human plasma (plasma derived concentrates) or genetically produced products (recombinant concentrates).

The primary objective of hemostatic hemophilia treatment is to prevent hemorrhages (prophylactic treatment continuously individualized) or to treat them as early and effective as possible with dosages, rate of administration and duration adapted to each case ("on-demand" therapy).

The onset of this haematological condition is early in severe forms of illness (F VIII $<1 \%$ ), in most patients even in the first year of life, when the baby begins to walk. Thus, for children with severe phenotype, long-term prophylactic substitution is recommended in order to permanently maintain a $\mathrm{F}$ VIII concentration above $1 \%$ (minimum value to prevent spontaneous bleeding) $(3,4)$.

Primary prophylaxis should be initiated as soon as possible after diagnosis, before or immediately after the first haemarthrosis episode, and should be 
continued for at least the entire period of childhood and adolescence. Establishing the regimen (dose and frequency) will depend on the age of the patient, the phenotype of bleeding, the intensity of physical activity, the patient's compliance with the treatment and the patient's legal owners (parents). Even in the case of closely monitored prophylaxis, minor, asymptomatic, recurrent intra-articular haemorrhages may occur which will lead to chronic arthropathy changes over time $(3,5)$.

When a haemarthrosis occurs, haemostatic therapy is associated with other general measures such as articular rest, local ice packs, certain physiotherapy procedures, in very rare cases of massive blood accumulations - intra-articular aspiration and subsequent medical recovery (2).

On-demand substitution treatment should be optimally administered within 2 hours of the onset of clinically apparent bleeding, and will be individualized depending on its location, plasma F VIII requiring haemostasis and the risk of severe complications.

In the absence of effective and rapid haemostasis, repeated bleeding episodes will evolve from acute hemarthrosis to subacute hemarthrosis and finally to chronic arthropathy, associating significant loss of muscle function and irreversible tendon retractions due to a vicious antalgic position (3).

Therefore, a periodic musculoskeletal assessment is very important or when a bleeding occurs, the clinical examination being complemented by an imaging technique (radiography, ultrasonography, nuclear magnetic resonance - with punctual indication for each case) $(3,4)$.

Ultrasonography is an effective, quick and accessible method of confirming and shaping the treatment of musculoskeletal bleedings in haemophilia (6-8). Also, numerous studies have shown the fact that ultrasonography is very useful in the diagnosis of asymptomatic articular bleeds $(5,6)$. As our study shows, the early diagnostic and monitoring of the acute bleeding episodes, both clinically and through ultrasonography, influences the replacement therapy, minimalizing the pathological modifications with severe chronic progression potential of muscles and joints (pseudo tumors and articular ankylosis) $(2,6,8,11)$.

In this paper, we present the results of our prospective study, carried out over a period of two years (January 1, 2012 - December 31, 2013), the purpose of which was to specify the role of ultrasonography in the diagnosis and treatment of mus- culoskeletal disorders in patients diagnosed with severe and moderate haemophilia A, in the Paediatric Department of the Fundeni Clinical Institute.

\section{OBJECTIVES}

The objectives of this study were:

1. The imagistic confirmation of the clinically observed musculoskeletal disorder;

2. The monitoring of the treatment efficiency and of its shaping;

3 . The correlation between the clinical remission and the imagistic one.

\section{METHOD}

The method involved 23 subjects with severe and moderate haemophilia A to serial ultrasonography in order to determine: the presence of intra-articular or muscular bleedings, their size, the evolution under treatment, the time when the complete clinical-imagistic remission is obtained.

The criteria for inclusion in the study:

- Boys between 1 and 18 years old, diagnosed with severe (factor VIII $<1 \%$ ) and moderate (factor VIII 1-5\%) haemophilia A

- The start of the bleeding - at maximum 48 hours before admission in the hospital

- Joint or muscular location of bleeds

- Compliance with the treatment assured by full hospital admission

The data has been processed from the patient medical charts.

\section{RESULTS}

The results of the ultrasonograms have described the following: muscular haematomas -3 patients $(12.9 \%)$, haemarthroses with synovial thickening - 12 patients $(52.6 \%)$, haemarthroses with synovial proliferation -8 patients $(35.5 \%)$. The ultrasonograms at admission have confirmed the suspected clinical diagnosis of haemarthrosis or muscular haematoma for 23 patients $(100 \%)$ in the studied group. 20 patients $(86.9 \%)$ required the continuation of the replacement treatment on average for 2 days after the clinical resolution, until the imagistic resolution was obtained. Complete simultaneous clinical-imagistic remission was achieved in a single patient $(4.3 \%)$. For 2 patients $(8.6 \%)$, both the diagnostic and the monitoring until resolution have been confirmed only by ultrasonography. 
TABLE 1. The average age of the patients was 10.65 years

\begin{tabular}{|c|c|c|c|c|c|c|c|}
\hline Patient & $\begin{array}{c}\text { Muscular } \\
\text { Hematom Location }\end{array}$ & $\begin{array}{l}\text { Hemarthrosis } \\
\text { Location }\end{array}$ & Synovium & $\begin{array}{c}\text { Clinical } \\
\text { Diagnosis }\end{array}$ & $\begin{array}{l}\text { Ultrasound } \\
\text { Confirmation }\end{array}$ & $\begin{array}{c}\text { Days to } \\
\text { Clinical } \\
\text { Resolution }\end{array}$ & $\begin{array}{c}\text { Days to } \\
\text { Imaging } \\
\text { Resolution }\end{array}$ \\
\hline 1 & - & Right knee & Prolifera on & Yes & Yes & 4 & 6 \\
\hline 2 & - & Right knee & Prolifera on & Yes & Yes & 5 & 8 \\
\hline 3 & - & Right ankle & Prolifera on & Yes & Yes & 3 & 3 \\
\hline 4 & Iliopsoas & - & - & Yes & Yes & 13 & 21 \\
\hline 5 & & Le elbow & Thining & Yes & Yes & 3 & 4 \\
\hline 6 & - & Le ankle & Thining & No & Yes & - & 3 \\
\hline 7 & - & $\begin{array}{l}\text { Right popliteal } \\
\text { recess }\end{array}$ & Prolifera on & Yes & Yes & 6 & 8 \\
\hline 8 & - & Le knee & Prolifera on & Yes & Yes & 4 & 7 \\
\hline 9 & Femural le & - & - & Yes & Yes & 8 & 10 \\
\hline 10 & - & Right knee & Prolifera on & Yes & Yes & 5 & 6 \\
\hline 11 & - & Right ankle & Thining & No & Yes & - & 2 \\
\hline 12 & $\begin{array}{c}\text { Gastrocnemian } \\
\text { medial }\end{array}$ & - & - & Yes & Yes & 7 & 9 \\
\hline 13 & - & Right ankle & Thining & Yes & Yes & 3 & 4 \\
\hline 14 & - & $\begin{array}{l}\text { Le popliteal } \\
\text { recess }\end{array}$ & Prolifera on & Yes & Yes & 5 & 6 \\
\hline 15 & - & Le elbow & Thining & Yes & Yes & 3 & 4 \\
\hline 16 & - & Right ankle & Thining & Yes & Yes & 4 & 6 \\
\hline 17 & - & Le ankle & Thining & Yes & Yes & 4 & 5 \\
\hline 18 & - & Right elbow & Thining & Yes & Yes & 4 & 6 \\
\hline 19 & - & Right elbow & Thining & Yes & Yes & 3 & 4 \\
\hline 20 & - & Le elbow & Thining & Yes & Yes & 5 & 7 \\
\hline 21 & - & Le ankle & Thining & Yes & Yes & 2 & 3 \\
\hline 22 & - & Right ankle & Thining & Yes & Yes & 2 & 4 \\
\hline 23 & - & Right knee & Prolifera on & Yes & Yes & 4 & 6 \\
\hline
\end{tabular}

\section{DISCUSSIONS}

The joints represent the main localization $(>80$ $90 \%$ of people with haemophilia) of bleeding in severe or moderate haemophilia, with or without inhibitors, regardless of the age of the patient, which is also confirmed in the present study (20 patients with haemarthrosis $=86.9 \%$ of the patients in the study group) $(12,13)$.

In the absence of an adequate haemostatic treatment, the evolution is progressive from acute hemarthrosis to chronic arthropathy, leading to ankylosis and painful joint deformities that cause disability and reduced quality of life of these patients (patients can not take care of themselves). There are affected in chronological order the synovium, the cartilage and the bone, the joint exhibiting a degenerative aspect.

The prophylactic or on-demand substitution treatment with clotting factor concentrates aims to prevent the progressive irreversible process of joint damage (the most common target joints are the knees, the elbows and the ankles).
The iron released from hemoglobin and stored as hemosiderin as a result of repeated, asymptomatic or clinically evident intraarticular haemorrhages leads to a chronic inflammatory and degenerative reaction as well as to neo-angiogenesis, resulting in chronic synovial proliferation (present at $35.5 \%$ of the patients under study) and subsequent destruction of the cartilage and bone (not the case in any of the patients in the study) (12-16).

These processes are mediated by proinflammatory cytokines (IL-1 $\beta$, IL-1 $\alpha$, IL-6) and tumor necrosis factor $\mathrm{TNF} \alpha$, whose expression is activated by the presence of intraarticular iron $(13,17)$.

Muscle bleeding is the second incidence (10$23 \%)$, a fact confirmed by this study $(12.9 \%=3$ patients diagnosed with muscle haematomas). As with haemarthrosis, appropriate, prophylactic or curative hemostatic treatment is required to avoid the occurrence of severe complications, such as compartment syndrome, neuropathy, infections, pseudotumor formation, myositis ossificans (18).

Therefore, it is very important to prevent haemarthroses/hematomas or, when these occur, to obtain a full intra-articular/intramuscular blood re- 
mission as soon as possible. This can only be achieved by appropriate hemostatic treatment that will be administered until the ultrasound shows complete blood disappearance, which may follow some days after clinical resolution $(86.9 \%$ of the patients evaluated imaging resolution was achieved after mean 2 days vs. clinical one, only 1 patient = $4.3 \%$ there was clinical/imaging concordance). U1trasound has two roles: the first is confirmation of the intra-articular/intramuscular blood collection (in $100 \%$ of the cases studied); the second one is to appreciate the structural integrity of the joint / muscle (19-22).

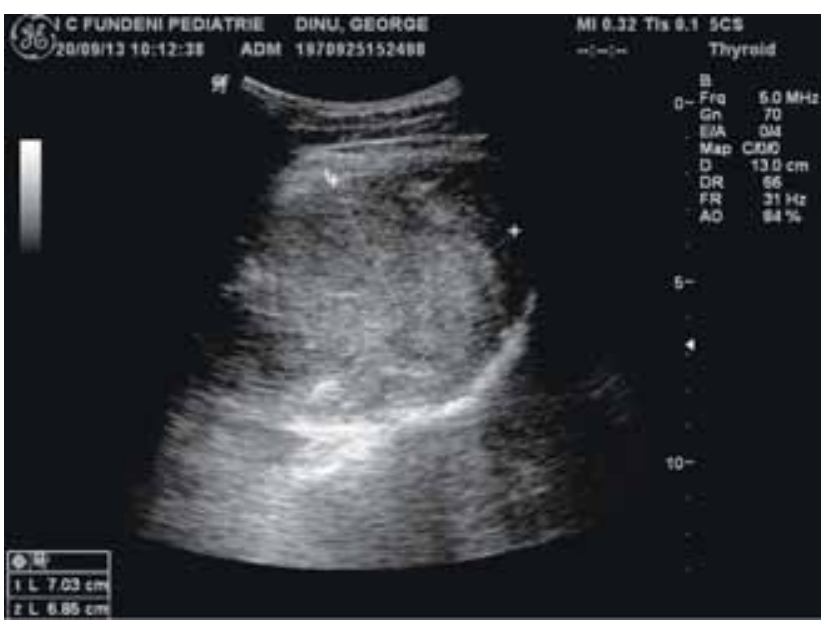

FIGURE 1. Predominantly hyperechogenous accumulation (the intensely hyperechogenous component matches an acute hemorrhage, under development at the time of examination) with intramuscular localization, on the level of the left-side iliopsoas muscular compartment on a child who is known to have hemophilia.

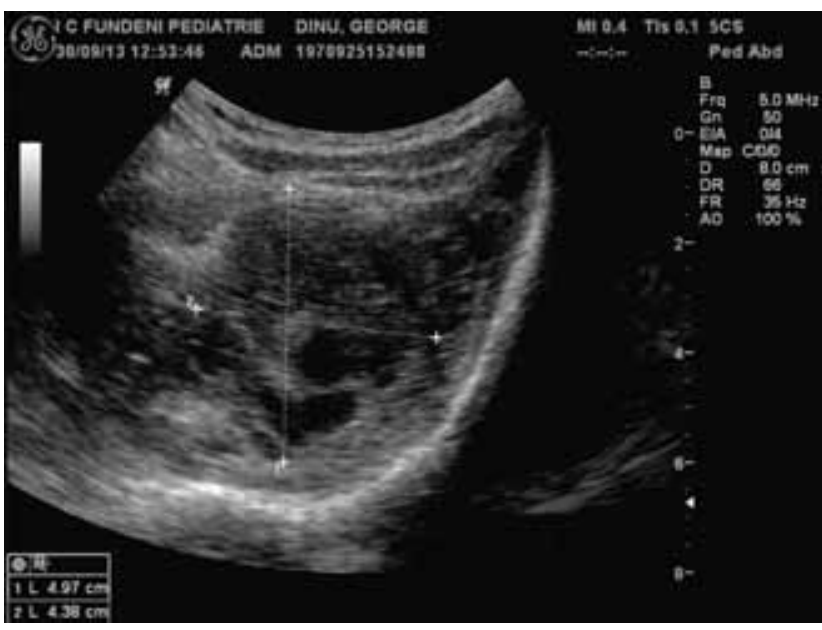

FIGURE 2. Under development, in the same patient as in Figure 1, the hematoma reduces its size and has a heterogeneous appearance (peripheral iso-/discrete hypoechogenic with a central hypoechogenic-transonic area matching the degraded blood).

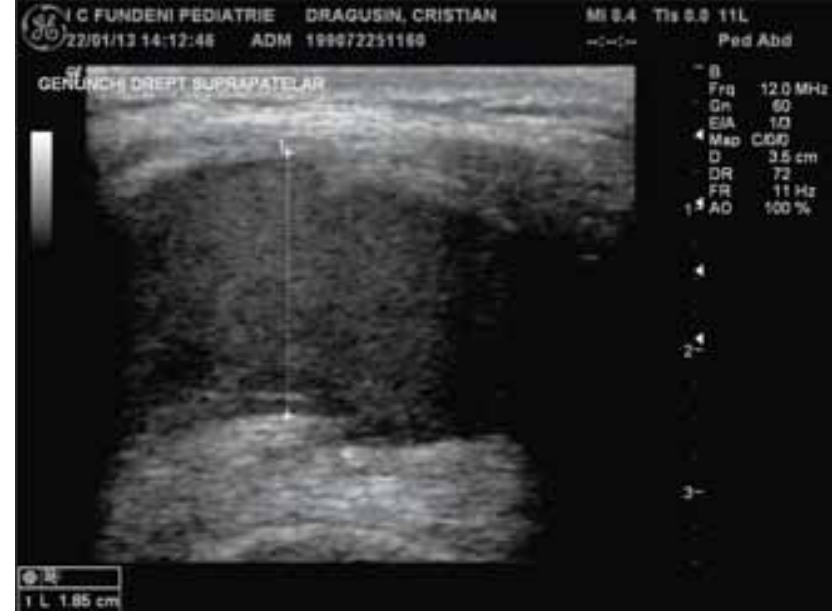

FIGURE 3. Acute intra-articular hematoma (right knee) in a child known to have severe hemophilia $A$ and inhibitors, with recent intra-articular bleeding

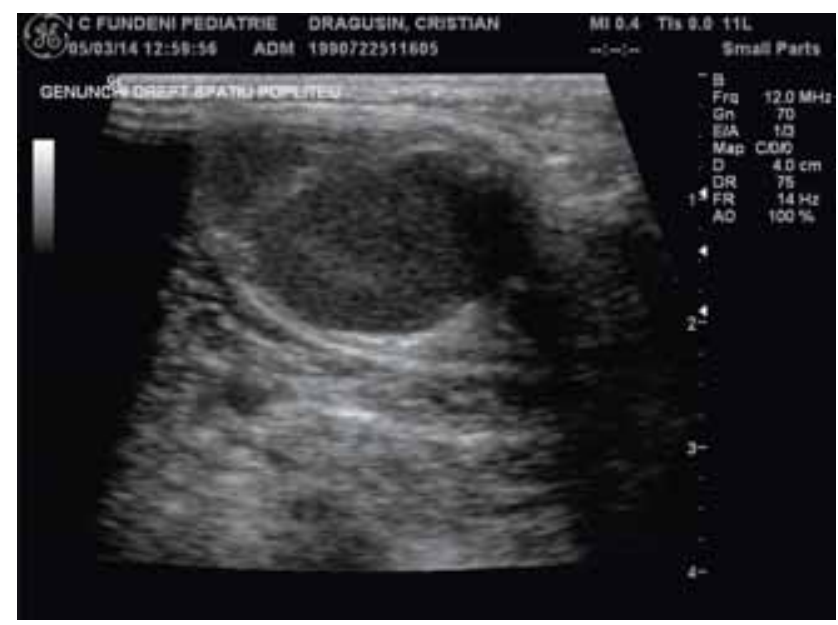

FIGURE 4. Polylobate, ovalar, well delimited accumulation (apparently encapsulated), heterogeneous through the presence of intralesional septums, compatible with acute hematoma, localized in the soft areas of the lower right popliteal fossa communicating with the articular space, in the same patient with severe hemophilia $A$ and inhibitors

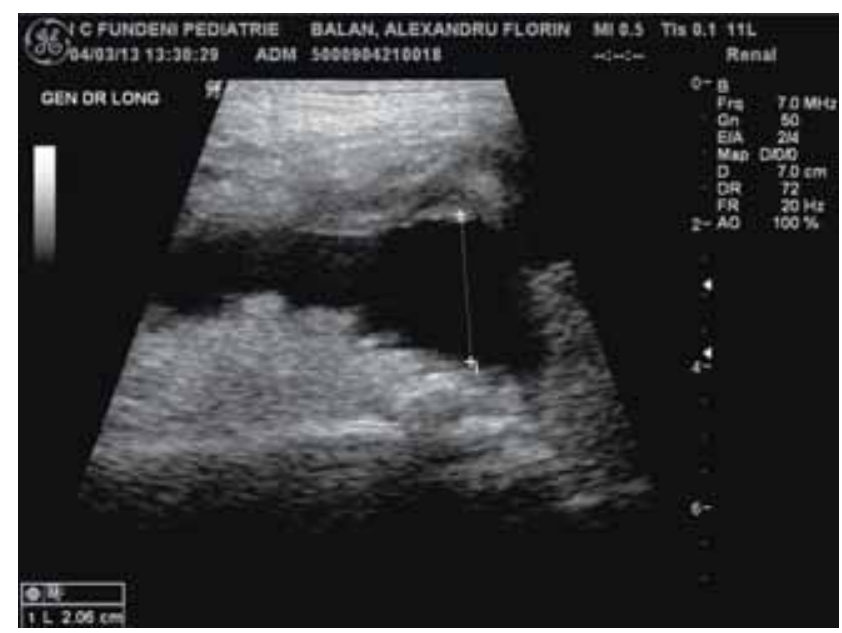

FIGURE 5. 


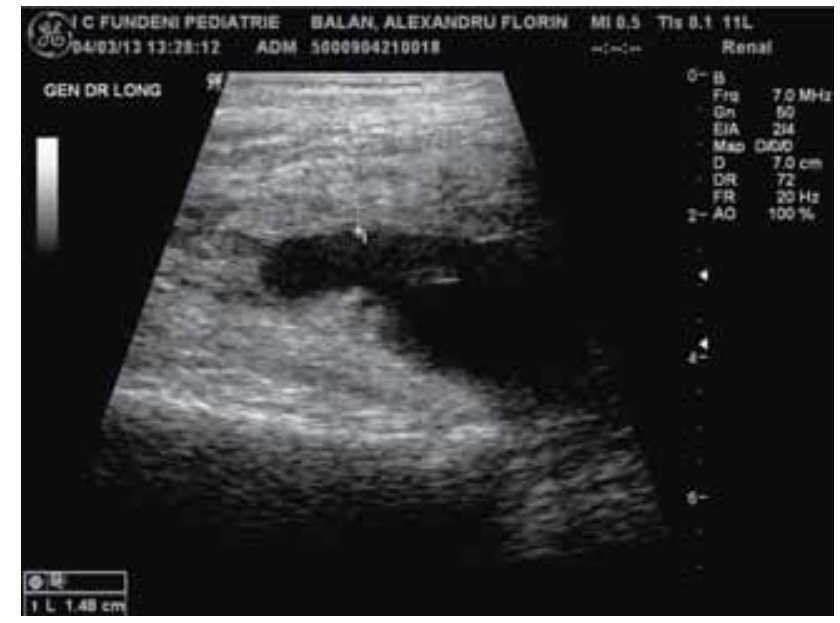

FIGURES 5 and 6. Transonic accumulation (persistent hematoma) on the right knee articulation level, associated to the significant synovial proliferation on this level, in a child with severe hemophilia A

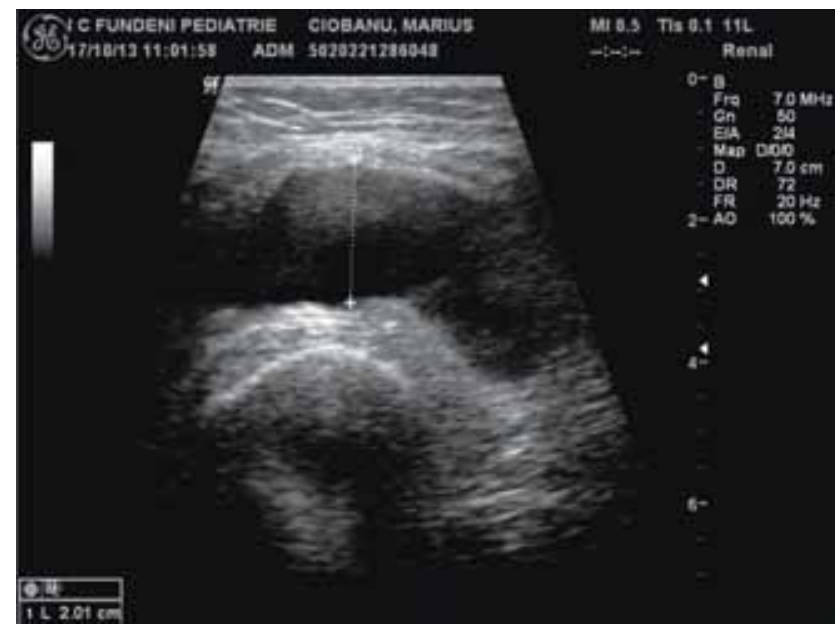

FIGURE 7. Hyperechogenous accumulation, relatively homogenous, localized at the right knee articulation level, predominantly in the suprapattelar recess, compatible with a hematoma under degradation, in a child known to have severe hemophilia $A$.

\section{CONCLUSIONS}

The minimization of chronic impairment with irreversible degenerative changes of the musculoskeletal system in severe and medium haemophilia is the main objective of caring for patients with this pathology.

The identification of early articular alterations and their evolving prevention can only be achieved by a complex periodic monitoring in specialized comprehensive centers. The ultrasound examination confirms the existence of localized or diffuse bleedings and provides accurate information on articular status and muscle compartment, starting from the description of some suggestive aspects of early impairment at these levels through asymptomatic bleeding that can not be clinically objectified until significant alterations with structural damage components (synovial, cartilage, bone, muscle fibers).

Ultrasound technique is fast, accessible and affordable, with a decisive role in adopting an optimal, personalized treatment to each haemorrhagic episode. Thus, by avoiding degenerative musculoskeletal progression secondary to hemorrhages, the quality of life of patients with hemophilia significantly improves.

Conflict of interest: none declared Financial support: none declared

\section{REFERENCES}

1. Guidelines for the Management of Hemophilia $2^{\text {nd }}$ edition 2012, World Federation of Hemophilia's website at www.wfh.org

2. Hermans C., De Moerloose P., Fischer K., Holstein K., Klamroth R., Lambert T., Lavigne-Lissalde G., Perez R., Richards M., Dolan G. Management of acute haemarthrosis in haemophilia A without inhibitors: literature review, European survey and recommendations; European Haemophilia Therapy Standardisation Board. Haemophilia. 2011 May;17(3):383-92. doi: 10.1111/j.1365-2516.2010.02449.x. Epub $2011 \mathrm{Feb} 15$

3. Lobet S., Hermans C., Lambert C. Optimal management of hemophilic arthropathy and hematomas. Journal of Blood Medicine 2014:5 207-218

4. Rodriguez-Merchan E.C., Jimenez-Yuste V., Aznar J.A. et al. Joint. protection in haemophilia. Haemophilia. 2011; 17 Suppl 2:1-23.

5. Blanchette V.S. Prophylaxis in the haemophilia population. Haemophilia. 2010;16 Suppl 5:181-188.

6. Aznar J.A., Abad-Franch L., Perez-Alenda S., Haya S., Cid A.R., Querol F. Ultrasonography in the monitoring of management of haemarthrosis. Haemophilia. 2011;17(5):826-828

7. Querol F., Rodriguez-Merchan E.C. The role of ultrasonography in the diagnosis of the musculo-skeletal problems of haemophilia. Haemophilia. 2012 May;18(3):e215-26. doi: 10.1111/j.1365-2516.2011.02680.x. Epub 2011 Nov 2.

8. Sierra Aisa C., Lucía Cuesta J.F., Rubio Martínez A., Fernández Mosteirín N., Iborra Muñoz A., Abío Calvete M., Guillén Gómez M., Moretó Quintana A., Rubio Félix D. Comparison of ultrasound and magnetic resonance imaging for diagnosis and follow-up of joint lesions in patients with haemophilia. Haemophilia. 2014 Jan;20(1):e51-7. doi: 10.1111/hae.12268. Epub 2013 Sep 24

9. Di Minno M.N., lervolino S., Soscia E., Tosetto A., Coppola A., Schiavulli M., Marrone E., Ruosi C., Salvatore M., Di Minno G. Magnetic resonance imaging and ultrasound evaluation of "healthy" joints in young subjects with severe haemophilia A. Haemophilia. 2013 May;19(3):e167-73. doi: 10.1111/hae.12107. Epub 2013 Mar 18.

10. Melchiorre D., Linari S., Innocenti M., Biscoglio I., Toigo M., Cerinic M.M., Morfini M. Ultrasound detects joint damage and bleeding in haemophilic arthropathy: a proposal of a score. 
Haemophilia. 2011 Jan;17(1):112-7. doi: 10.1111/j.1365-2516.2010.02380.x. Epub 2010 Nov 11.

11. Ceponis A., Wong-Sefidan I., Glass C.S. and A. Von D. Rapid musculoskeletal ultrasound for painful episodes in adult haemophilia patients. Haemophilia (2013), 1-9. DOI: 10.1111/hae.12175

12. Di Minno M.N., Pasta G., Airaldi S., Zaottini F., Storino A., Cimino E., Martinoli C. Ultrasound for Early Detection of Joint Disease in Patients with Hemophilic Arthropathy. J. Clin. Med. 2017, 6, 77; doi:10.3390/jcm6080077

13. Melchiorre D., Manetti M., Matucci-Cerinic M. Pathophysiology of Hemophilic Arthropathy. J. Clin. Med. 2017, 6, 63; doi:10.3390/ jcm6070063.

14. Eubank T.D., Galloway M., Montague C.M., Waldman W.J., Marsh C.B. M-CSF induces vascular endothelial growth factor production and angiogenic activity from human monocytes. J. Immunol. 2003; 171:2637-2643. doi: 10.4049/jimmunol.171.5.2637.

15. Zetterberg E., Palmblad J., Wallensten R., Morfini M., Melchiorre D., Holmström M. Angiogenesis is increased in advanced haemophilic joint disease and characterized by normal pericyte coverage. Eur. J. Haematol. 2014; 92:256-262. doi: 10.1111/ ejh. 12227

16. Acharya S., Kaplan R., Macdonald D., Fabiyi O., Dimichele D., Lyden D. (2011) Neoangiogenesis contributes to the development of hemophilic synovitis. Blood 117: 2484-2493
17. Ovlisen K., Kristensen A.T., Jensen A.L., Tranholm M. IL-1 beta, IL-6, KC and MCP-1 are elevated in synovial fluid from haemophilic mice with experimentally induced haemarthrosis. Haemophilia. 2009; 15:802-810. doi: 10.1111/j.1365-2516.2008.01973.x.

18. De la Corte-Rodriguez H., Rodriguez-Merchan E.C. Treatment of muscle haematomas in haemophiliacs with special emphasis on percutaneous drainage. Blood Coagul Fibrinolysis. 2014 Dec; 25(8):787-94. doi: 10.1097/MBC.0000000000000159.

19. Melchiorre D., Linari S., Innocenti M., Biscoglio I., Toigo M., Cerinic M.M., Morfini M. Ultrasound detects joint damage and bleeding in haemophilic arthropathy: A proposal of a score. Haemophilia. 2011; 17:112-117. doi: 10.1111/j.1365-2516.2010.02380

20. Ceponis A., Wong-Sefidan I., Glass C., Von Drygalski A. (2013) Rapid musculoskeletal ultrasound for painful episodes in adult haemophilia patients. Haemophilia 19: 790-798

21. Doria A., Keshava S., Mohanta A., Jarrin J., Blanchette V., Srivastava A., et al. (2015) Diagnostic accuracy of ultrasound for assessment of hemophilic arthropathy: MRI correlation. AJR Am J Roentgenol 204: W336-W347

22. Muca-Perja M., Riva S., Grochowska B., Mangiafico L., Mago D., Gringeri A. (2012) Ultrasonography of haemophilic arthropathy. Haemophilia 18: 364-368 